\title{
Correction to: Comparison between submucosal tunneling endoscopic resection and video-assisted thoracoscopic enucleation for esophageal submucosal tumors originating from the muscularis propria layer: a randomized controlled trial
}

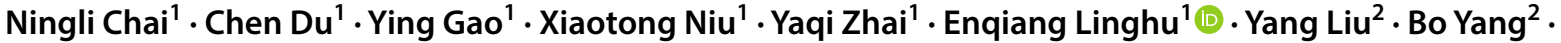 \\ Zhongsheng $\mathrm{Lu}^{1} \cdot{\text { Zhenjuan } \mathrm{Li}^{1} \cdot \text { Xiangdong Wang }}^{1}$ · Ping Tang ${ }^{1}$
}

Published online: 23 March 2018

(c) Springer Science+Business Media, LLC, part of Springer Nature 2018

\section{Correction to: Surgical Endoscopy https://doi.org/10.1007/s00464-018-6057-8}

In the original article, there are two errors in Table 3:

1. There were 8 patients undergoing VATE suffer from moderate fever, not 9 .

2. In the fourth line of outcomes, saying "pneumothorax, moderate fever and moderate fever," "moderate fever" was repeated.

The corrected Table 3 is shown here. The authors regret the errors.
Table 3 Safety outcomes in the STER and VATE groups

\begin{tabular}{lll}
\hline Outcomes & STER $(\mathrm{n}=30)$ & VATE $(\mathrm{n}=28)$ \\
\hline $\begin{array}{l}\text { Subcutaneous or mediastinal emphy- } \\
\quad 3\end{array}$ & 0 \\
$\quad$ sema & 1 & 8 \\
Moderate fever & 0 & 1 \\
Severe chest pain & 1 & 0 \\
Pneumothorax and moderate fever & 0 & 1 \\
Moderate fever, severe chest pain & 0 & \\
$\quad$ and ventricular fibrillation & & $10(35.7 \%)$ \\
Total AEs, n $(\%)$ & $5(16.7 \%)$ &
\end{tabular}

STER submucosal tunneling endoscopic resection, VATE videoassisted thoracoscopic enucleation, $A E$ adverse event
The original article can be found online at https://doi.org/10.1007/ s00464-018-6057-8.

Enqiang Linghu

linghuenqiang@vip.sina.com

1 Department of Gastroenterology and Hepatology, Chinese PLA General Hospital, Fuxing Road 28. Haidian District, Beijing, People's Republic of China

2 Department of Thoracic Surgery, Chinese PLA General Hospital, Beijing, People's Republic of China 